\title{
Systematically Controlled Decomposition Mechanism in Phosphorus Flame Retardants by Precise Molecular Architecture: $\mathrm{P}-\mathrm{O}$ vs $\mathrm{P}-\mathrm{N}$
}

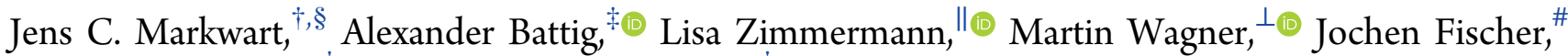

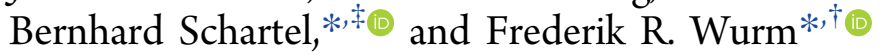 \\ ${ }^{\dagger}$ Physical Chemistry of Polymers, Max Planck Institute for Polymer Research, Ackermannweg 10, 55128 Mainz, Germany \\ ${ }^{\ddagger}$ Bundesanstalt für Materialforschung und -prüfung (BAM), Unter den Eichen 87, 12205 Berlin, Germany \\ ${ }^{\S}$ Graduate School Materials Science in Mainz, Staudinger Weg 9, 55128 Mainz, Germany \\ "Department of Aquatic Ecotoxicology, Goethe University Frankfurt, Max-von-Laue-Str. 13, 60438 Frankfurt/Main, Germany \\ ${ }^{\perp}$ Department of Biology, Norwegian University of Science and Technology, 7491 Trondheim, Norway \\ \#Institute for Biotechnology and Drug Research gGmbH (IBWF), Erwin-Schrödinger-Str. 56, 67663 Kaiserslautern, Germany
}

Supporting Information

ABSTRACT: Flame retardants (FR) are inevitable additives to many plastics. Halogenated organics are effective FRs but are controversially discussed due to the release of toxic gases during a fire or their persistence if landfilled. Phosphorus-containing compounds are effective alternatives to halogenated FRs and have potential lower toxicity and degradability. In addition, nitrogencontaining additives were reported to induce synergistic effects with phosphorus-based FRs. However, no systematic study of the gradual variation on a single phosphorus $\mathrm{FR}$ containing both $\mathrm{P}-\mathrm{O}$ and $\mathrm{P}-$ $\mathrm{N}$ moieties and their comparison to the respective blends of

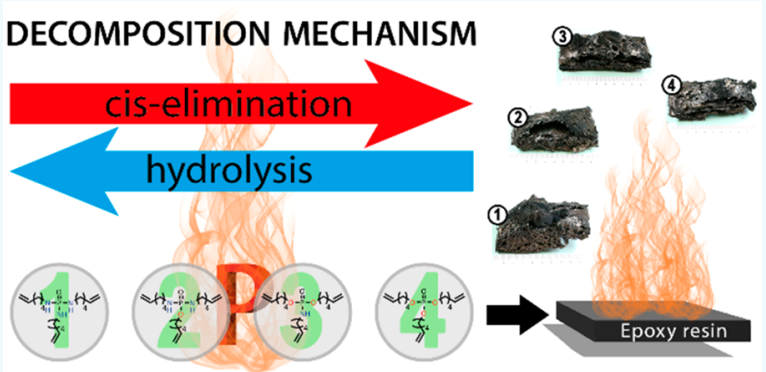
phosphates and phosphoramides was reported. This study developed general design principles for $\mathrm{P}-\mathrm{O}-$ and $\mathrm{P}-\mathrm{N}$-based $\mathrm{FRs}$ and will help to design effective FRs for various polymers. We synthesized a library of phosphorus FRs that only differ in their P-binding pattern from each other and studied their decomposition mechanism in epoxy resins. Systematic control over the decomposition pathways of phosphate $\left(\mathrm{P}=\mathrm{O}(\mathrm{OR})_{3}\right)$, phosphoramidate $\left(\mathrm{P}=\mathrm{O}(\mathrm{OR})_{2}(\mathrm{NHR})\right)$, phosphorodiamidate $\left(\mathrm{P}=\mathrm{O}(\mathrm{OR})(\mathrm{NHR})_{2}\right)$, phosphoramide $\left(\mathrm{P}=\mathrm{O}(\mathrm{NHR})_{3}\right)$, and their blends was identified, for example, by reducing cis-elimination and the formation of $\mathrm{P}-\mathrm{N}$-rich char with increasing nitrogen content in the P-binding sphere. Our FR epoxy resins can compete with commercial FRs in most cases, but we proved that the blending of esters and amides outperformed the single-molecule amidates/diamidates due to distinctively different decomposition mechanisms acting synergistically when blended.

KEYWORDS: phosphorus, flame retardants, epoxies, mechanistic study, toxicity

\section{INTRODUCTION}

Polymers are omnipresent in our everyday life. However, their inherent risk of fire makes the use of flame retardants (FRs) inevitable. For this purpose, halogenated organics were used as effective FRs, but today these are controversially debated due to the release of toxic gases during a fire or their persistence if discarded. Currently, organophosphates are discussed as promising alternatives to halogenated FRs due to their effective flame-retardant properties and potential to design nontoxic and biodegradable FRs. ${ }^{1}$

The combination of phosphorus FRs (P-FRs) with additional nitrogen-containing additives resulted in synergistic effects during a fire by forming phosphorus-nitrogen intermediates or an increased charring. ${ }^{2}$ However, a systematic study of precisely synthesized P-FRs with a variable number of $\mathrm{P}-\mathrm{N}$ bonds (such as phosphoramidates and phosphorodiamidates, Figure 1) has not been performed. We prepared a series of aliphatic organophosphates/-amides (1-4) with a precise binding pattern around the central phosphorus and used them as a FR additive in epoxy resins. Their in vitro toxicity was also assessed and compared to commercial halogenated or other organophosphate-based FRs. Importantly, the effects of the Pbinding pattern $(1-4)$ have been studied during a fire scene to understand their decomposition pathway and compared to blends of phosphate and phosphoramide (these are 1 and 4) on the performance during a simulated fire scenario.

These P-FRs mainly differ in their main mode of action, which are gas and condensed phase activity. In the condensed phase, phosphorus-containing materials exhibit FR properties due to the enhanced formation and stabilization of carbona-

Received: February 12, 2019

Accepted: April 23, 2019

Published: April 23, 2019 

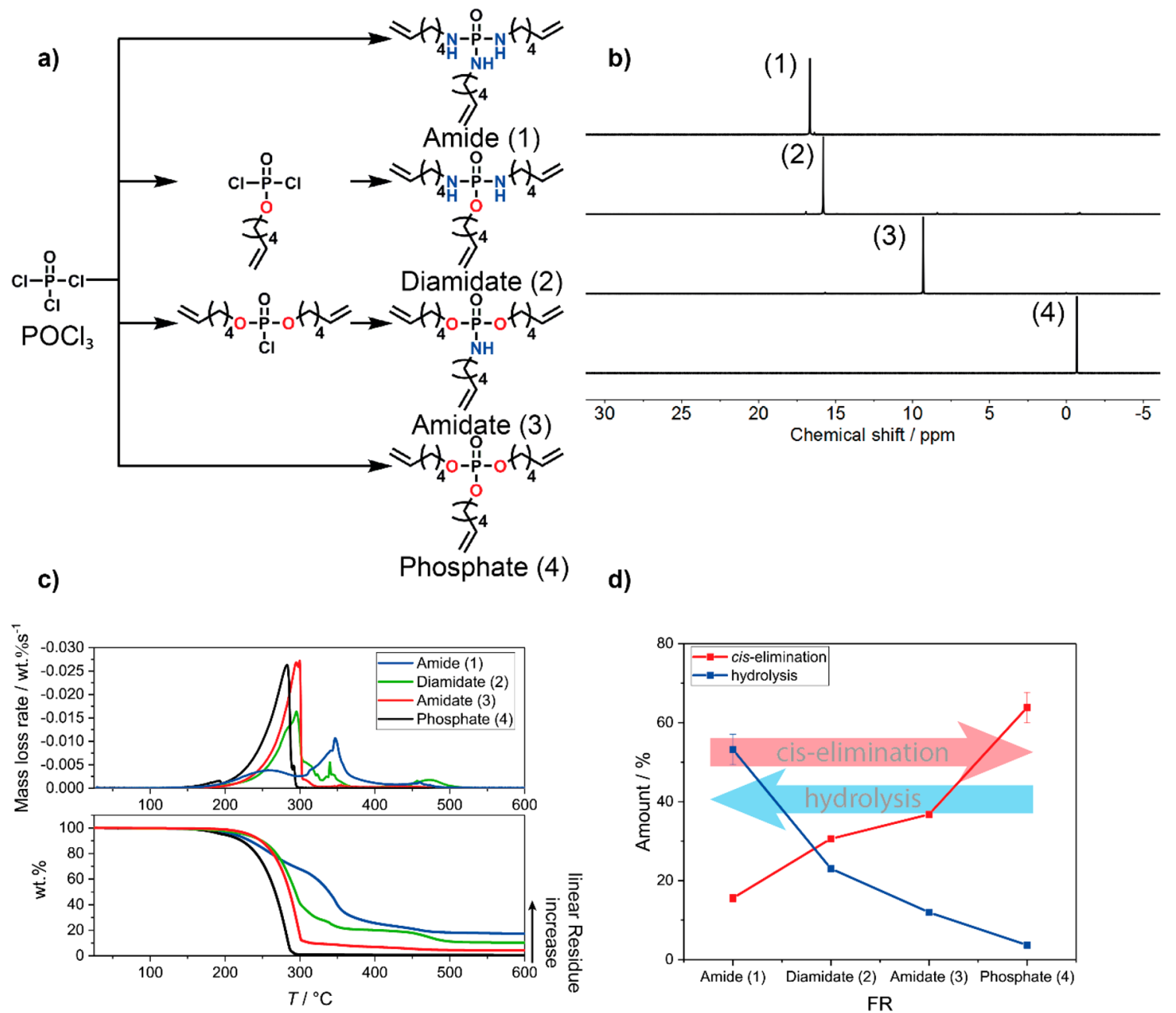

Figure 1. Characterization of flame retardants: amide (1), diamidate (2), amidate (3), and phosphate (4) (a) Schematic representation of the synthesis: the amide (1) and phosphate (4) are a one-step synthesis and the diamidate $(\mathbf{2})$ and amidate $(3)$ are a two-step synthesis. $(\mathrm{b}){ }^{31} \mathrm{P}-\left\{{ }^{1} \mathrm{H}\right\}$ NMR of the flame retardants in $\mathrm{CDCl}_{3}$. (c) Mass loss of the flame retardants in thermogravimetric tests; char yield increase with increasing nitrogen content. (d) Correlation of relative amount of cis-elimination and hydrolysis in the released gases during pyrolysis GC-MS (connection between the data points are only to guide the eye).

ceous char, which retains fuel in the condensed phase. Additionally, an intumescent multicellular char may protect the underlying polymer from heat, acting as a heat shield. ${ }^{3-5}$ The increased charring is explained by dehydration of the polymer and the formation of phosphoric acid derivatives, leading to cross-linking and aromatization. ${ }^{6}$ Activity in the gas phase is mainly due to the formation of PO radicals, slowing down the exothermic radical process in the combustion zone, leading to a reduced combustion efficiency and therefore reducing the heat release. ${ }^{4,7,8}$

The phosphorus-nitrogen synergism accelerates the polymer phosphorylation by increasing the in situ production of phosphoric acid due to catalyzing cis-elimination. The same is true for $\mathrm{P}-\mathrm{N}$ bonds, which are more reactive than $\mathrm{P}-\mathrm{O}$ bonds regarding the phosphorylation process. This retains phosphorus in the condensed phase and therefore promotes char formation and stabilization. ${ }^{10}$ Furthermore, $\mathrm{P}$ and $\mathrm{N}$ react to form thermally stable polymeric compounds in the condensed phase. ${ }^{9}$ While studies have shown the impact of nitrogen- and phosphorus-containing FRs, ${ }^{11,12}$ systematic studies on the gradual variation of the phosphorus binding pattern and its impact on the FR mechanism are rare. ${ }^{6}$ In addition, the comparison of phosphoramidates and phosphorodiamidates produced via chemical synthesis against blending the respective phosphate and phosphoramide, hitherto uninvestigated, is presented herein. The P-FRs are synthesized and characterized in detail on the molecular level; for example, degradation temperature and pathway are assessed. They are used as additive FRs in epoxy resins and are investigated in a simulated fire scenario with state-of-the-art techniques (LOI, UL-94, and cone calorimeter).

The knowledge about the varying decomposition mechanisms for combined $\mathrm{P}-\mathrm{O}$ - and $\mathrm{P}-\mathrm{N}$-based FRs will help the future preparation of biofriendly and effective FRs for various polymer materials since there is no universal FR design. FRs are optimized for a special application and matrix. For this task, it is important to know how the FR degrades to estimate possible interactions between matrix and FRs during a fire scenario. $^{13}$

\section{RESULTS AND DISCUSSION}

Synthesis and Design of Materials. To investigate the influence of the $\mathrm{P}-\mathrm{O}$ vs $\mathrm{P}-\mathrm{N}$ ratio on $\mathrm{FR}$ efficiency, a systematic library of organophosphates/-amidates is necessary. Four P-FRs with a central phosphorus atom and three $\omega$ - 


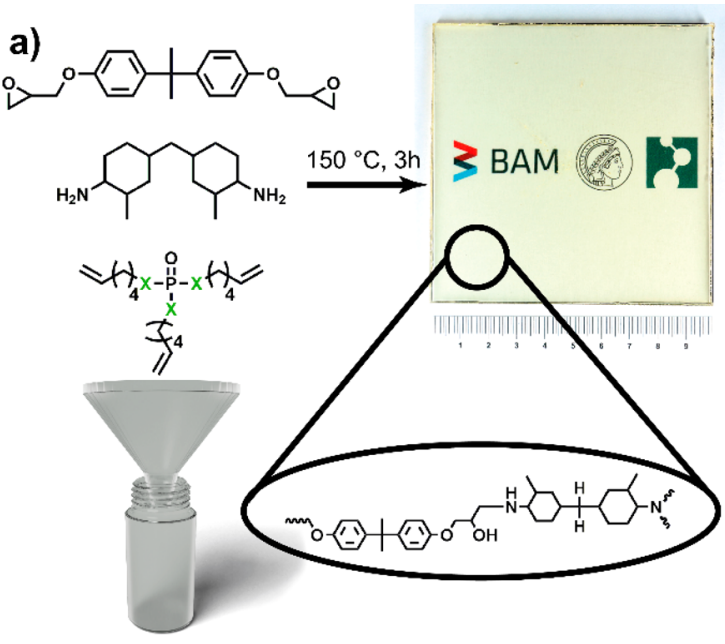

b)

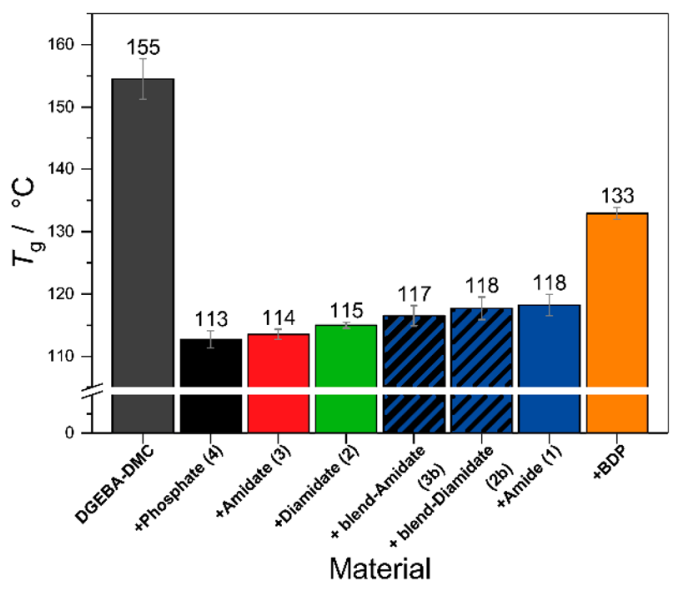

c)

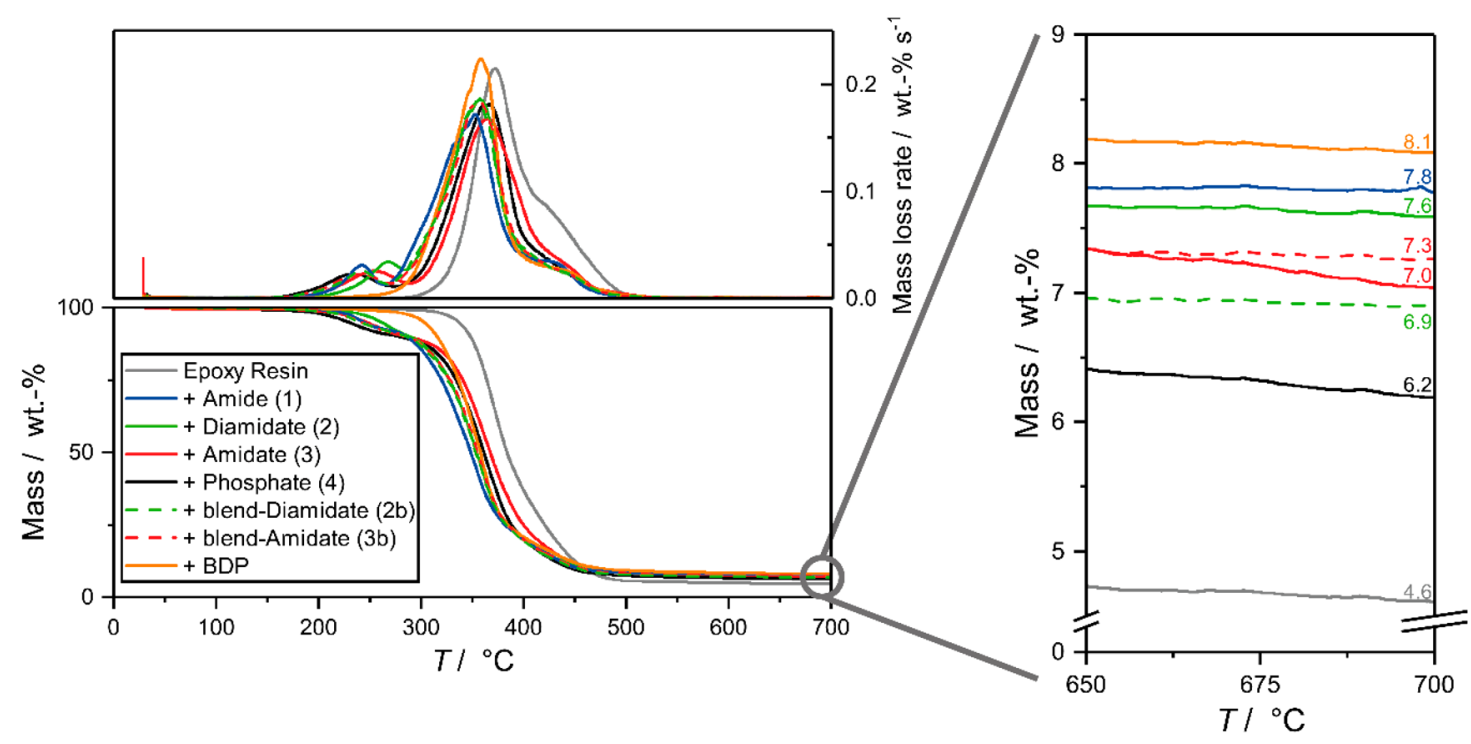

Figure 2. Characterization of flame-retarded epoxy resins. (a) Schematic representation of the epoxy resin synthesis. (b) Glass transition temperature of epoxy resin and flame-retarded composites. (c) Thermogravimetry $\left(10 \mathrm{~K} \mathrm{~min}^{-1} ; \mathrm{N}_{2}\right)$ of the epoxy resins with FRs; increase of char yield with increasing nitrogen content of the flame retardant.

hexenyl chains were synthesized. The organic side chains ensure miscibility with the epoxy matrix, and the double bonds were introduced to increase the charring performance. ${ }^{14,15}$ Tri(hex-5-en-1-yl)phosphoramide (1), tri(hex-5-en-1-yl)phosphorodiamidate (2), tri(hex-5-en-1-yl)phosphoramidate (3), and tri(hex-5-en-1-yl)phosphate (4) were synthesized starting from $\mathrm{POCl}_{3}$ via esterification with 5-hexen-1-ol or amidation with hex-5-en-1-amine (Figure 1a). The phosphoramide (1) and the phosphate (4) were prepared in a single step. In contrast, the phosphorodiamidate (2) and the phosphoramidate (3) were synthesized in two steps to guarantee the correct binding pattern, first by esterification followed by the amidation (the amidation as the first step may result in multiple amidations). All P-FRs were of sufficient purity after the synthesis without the need for additional purification steps as proven by ${ }^{1} \mathrm{H}$ and ${ }^{31} \mathrm{P}$ NMR spectra (Figures S2-S13 and Figure 1b). ${ }^{31} \mathrm{P}$ NMR spectroscopy is a precise technique to control the correct binding pattern and purity of the compounds: the phosphate exhibited a single resonance at $-0.67 \mathrm{ppm}$, whereas the signal shifted downfield with increasing nitrogen content (Figure 1b). By these procedures, all P-FRs were easily available up to at least $50 \mathrm{~g}$ with standard university lab equipment.

Organophosphorus compounds are currently considered as alternatives for halogenated $\mathrm{FRs}^{16,17}$ due to their potentially lower toxicity. ${ }^{18-20}$ To evaluate their toxicity, we tested $\mathbf{1 - 4}$ in fungi and plant cells. Additionally, we used reporter gene assays based on yeast and human cells to assess their baseline toxicity and endocrine activities (estrogenic and antiandrogenic). Compounds 1, 2, and 4 induced baseline toxicity increasing in the following order $(4<2<1)$ but were less toxic than the halogenated commercial tetrabromo bisphenol A (see the Supporting Information for details). While none of the compounds were estrogenic, 3 and 4 induced some antiandrogenic activity $(4<3)$. Although the compounds partly induced toxicity, the actual concentrations of FRs leaching from finished products still need to be determined.

Decomposition Studies. Phosphoramides exhibit higher thermal stability, lower volatility, and higher viscosity due to additional hydrogen bonding compared to their analogue phosphates. ${ }^{21}$ These properties may increase the overlap of the decomposition temperatures of both matrix and flame 
retardant. This overlap leads to higher reactivity during the pyrolysis and an increased residue amount as a higher phosphorus content is maintained in the condensed phase due to interactions of the FR with the matrix and their respective decomposition products. ${ }^{22,23}$

The combination of TGA, FTIR, and pyrolysis GC-MS gave a deeper insight into how the FRs decompose under pyrolytic conditions.

For the pure FRs (1-4) mass loss under pyrolysis, measured by thermogravimetric analysis (TGA, Figure 1c), proved the gradual change of the decomposition behavior according to the structure variation from 1 to 4 ; this already suggests a possible effect on the FR mechanism during a fire. The phosphoramide (1) proved the highest decomposition temperature $\left(T_{\max }\right)$ at $317^{\circ} \mathrm{C}$, which decreased with increasing $\mathrm{O}$ content of the FR to $274{ }^{\circ} \mathrm{C}$ for $2,269{ }^{\circ} \mathrm{C}$ for 3 , and $250{ }^{\circ} \mathrm{C}$ for 4 . In addition, the char yield (measured at $600{ }^{\circ} \mathrm{C}$ ) decreased from 1 with 17 wt $\%$ to $<1 \mathrm{wt} \%$ for 4 , indicating a different activity of the pure compounds in the gas and/or condensed phase. The phosphate decomposition curve followed a typical behavior of a vaporizing material with a clear boiling point while with increasing nitrogen content the degradation occurs via multiple decomposition steps over a broader temperature range. As $\mathrm{P}-$ $\mathrm{N}$ bonds are present in the FR, they can form more stable intermediates through a polymerization process that require higher amounts of thermal energy to vaporize, if at all, as is noticeable by the subsequent increase in $T_{\max }$ and higher amount of residue for each additional nitrogen introduced.

The FTIR spectra from the evolved gases (measured at $T_{\max }$ Figure S18) proved the presence of several decomposition products, among them those that correspond to hydrolysis products, i.e., 5-hexen-1-ol and hex-5-en-1-amine (after scission of the $\mathrm{P}-\mathrm{O}$ or $\mathrm{P}-\mathrm{N}$ bond, respectively). The spectra also indicated the presence of derivatives containing $\mathrm{P}=\mathrm{O}$ and $\mathrm{P}-\mathrm{O}$ moieties at 1299 and $1030 \mathrm{~cm}^{-1}$ for the phosphate (4), while we detected additional vibrations for the $\left(\mathrm{NH}_{2}\right)-\mathrm{P}=\mathrm{O}$ band at $1159 \mathrm{~cm}^{-1}$ during the decomposition of 2 and 3 . In addition, all nitrogen-containing P-FRs exhibited $\mathrm{C}-\mathrm{N}$ bands at $1075 \mathrm{~cm}^{-1}, \mathrm{P}-\mathrm{N}-\mathrm{C}$ or $\mathrm{P}-\mathrm{N}-\mathrm{P}$ bands at $980 \mathrm{~cm}^{-1}$, and $\mathrm{N}-$ $\mathrm{H}$ bands at $769 \mathrm{~cm}^{-1}$. For all nitrogen-containing FRs at higher temperatures $\left(T>T_{\max }\right) \mathrm{P}-\mathrm{N}$ bands between 1330 and $1300 \mathrm{~cm}^{-1}$ and two characteristic bands for ammonia at 965 and $930 \mathrm{~cm}^{-1}$ were detected, albeit shifted or overlapped with other signals, pointing to the formation of incombustible gas resulting in flame dilution.

Pyrolysis GC-MS supports these results and further proves the presence of the major decomposition products. Compound 4 decomposed mainly by a cis-elimination during pyrolysis as indicated by the high amount of 1,5-hexadiene which was detected at a retention time of $2.6 \mathrm{~min}$ (Figure S29). Also, the other $\mathrm{P}-\mathrm{O}$-containing FRs (2 and 3) released 1,5-hexadiene during decomposition, but the amount of cis-elimination decreased with increasing $\mathrm{P}-\mathrm{N}$ content (Figure 1d). Additionally, 5-hexen-1-amine and 5-hexen-1-ol were detected for 2 and 3 (retention at 6.1 and $6.7 \mathrm{~min}$ in Figure S29). Additionally, for 2-4, phosphoric acid derivatives at retention times of 23.7, 24.6, and $25.8 \mathrm{~min}$ were identified, corresponding to the gas-phase activity of such compounds. Because of transesterifications during the decomposition, in the GC elugrams of $\mathbf{3}$, also compound 4 was detected, while in the elugram of the pyrolysis GC-MS of 2 , transesterification leads to the formation of $\mathbf{3}$ and $\mathbf{4}$. In stark contrast, during the decomposition of $\mathbf{1}$, almost no cis-elimination occurred, and only little amounts of phosphoric acid derivatives were observed, indicating the formation of nonvolatiles and thus underlining the condensed phase activity of the phosphoramide. This was further supported by solid-state ${ }^{31} \mathrm{P}$ NMR of the char residues, which exhibited distinct signals for $\mathrm{P}-\mathrm{N}$ compounds (Figure S46).

Flame-Retardant Behavior in Epoxies. The FR performances of 1-4 and blends of 1 and 4 were studied in an epoxy resin based on bisphenol A diglycidyl ether (DGEBA) and 2,2'-dimethyl-4,4'-methylenebis(cyclohexylamine) (DMC). The epoxy plates were prepared by mixing DGEBA with DMC in the presence of 10 wt \% of each FR in an aluminum mold and curing for $3 \mathrm{~h}$ at $150{ }^{\circ} \mathrm{C}$ (Figure $2 \mathrm{a}$ ). As the P-NHR bond may also act as a curing agent under certain conditions, we performed a control experiment with $\mathbf{1}$ and phenyl glycidyl ether at the curing conditions for the epoxy. Under the crosslinking conditions, no ring-opening of the epoxide occurred from the P-NHR bond (cf. Figures S14-S16), proving that 13 act as additive, and not reactive, FRs. As a benchmark, the commercially available and industrially used FR bisphenol A diphenyl phosphate (BDP) was chosen, as it was already used successfully in epoxy resins. ${ }^{24,25}$

Typically, additive FRs act as plasticizers of the epoxy resin and reduce the glass transition temperature $\left(T_{\mathrm{g}}\right)$. All flameretarded epoxy resins with 10 wt $\% 1,2,3$, or 4 also exhibited lower $T_{\mathrm{g}} \mathrm{s}$ by $36-42{ }^{\circ} \mathrm{C}$ compared to the neat epoxy resin. 4 shows the highest decrease of $T_{\mathrm{g}}$ (to $113{ }^{\circ} \mathrm{C}$ ), while with increasing amount of $\mathrm{NH}$ bonds an increase of the $T_{\mathrm{g}} \mathrm{s}$ was detected, probably due to hydrogen-bonding effects (Figure $2 \mathrm{~b})$. Blending of 1 and 4 in a $1: 2$ or $2: 1$ molar ratio to "simulate" the elemental composition of a phosphoramidate (3b) and phosphorodiamidate (2b) resulted in a slightly higher $T_{\mathrm{g}}$ compared to the pure $\mathbf{2}$ and $\mathbf{3}$ was detected. For $\mathrm{BDP}$, the $T_{\mathrm{g}}$ of the neat epoxy $\left(155^{\circ} \mathrm{C}\right)$ was reduced to $133{ }^{\circ} \mathrm{C}$. In all cases, the aliphatic FRs $1-4$ result in a higher decrease of $T_{\mathrm{g}}$ compared to the stiff aromatic BDP. ${ }^{26}$

To understand the differences of $\mathbf{1 - 4}$ (and $\mathbf{2 b}$ and $\mathbf{3 b}$ ) on the behavior of the loaded epoxies during combustion, we elucidated the FR mode of actions and mechanisms. A crucial step toward understanding the FR mechanisms is analyzing the pyrolysis of the epoxy resins with FRs by TGA. The burning with a stable flame is dominated by an anaerobe pyrolysis, producing volatile fuel that is combusted in the flame. This model suits most polymeric materials in most fire scenarios such as ignition and developing fires and thus for all the important fire tests for polymeric materials, such as UL 94, LOI, and flaming combustion in the cone calorimeter. Although the heating rate is relatively slow, thermogravimetry under nitrogen is the best common analytical method to investigate the pyrolysis controlling the burning of polymeric materials. ${ }^{27}$ A lower onset temperature of the degradation for the FR epoxies was detected compared to the neat epoxy. This was attributed to volatilization of the FRs and is indicated by an additional decomposition step equal to $\sim 10 \mathrm{wt} \%$. Notably, however, the main decomposition step shifts to higher temperatures with increasing amount of $\mathrm{P}-\mathrm{O}$ bonds in the additive. Importantly, for all FR epoxy resins, an increased char yield was detected, which further increased slightly with increasing $\mathrm{P}-\mathrm{N}$ bonds in the FRs (Figure 2c).

While microscale experiments aid in understanding certain aspects of a material's fire-retardant properties, they do not fully evaluate fire behavior on a macroscopic scale. Two reaction-to-small-flame tests were conducted, namely limiting 
a)

\begin{tabular}{|c|c|c|c|c|c|c|}
\hline $\begin{array}{l}\text { Material } \\
\text { composition }\end{array}$ & $\begin{array}{r}\text { DGEBA- } \\
\text { DMC }\end{array}$ & $\begin{array}{r}+ \text { Amide } \\
(1)\end{array}$ & $\begin{array}{r}\text { + Diamidate } \\
\text { (2) }\end{array}$ & $\begin{array}{r}+ \text { Amidate } \\
\text { (3) }\end{array}$ & $\begin{array}{r}+ \text { Phosphate } \\
(4) \\
\end{array}$ & $+\mathrm{BDP}$ \\
\hline \multicolumn{7}{|l|}{ LOI } \\
\hline$[\mathrm{c}(\mathrm{O} 2)] / \%$ & $18.7 \pm 0.3$ & $22.9 \pm 0.2$ & $23.3 \pm 0.2$ & $22.8 \pm 0.2$ & $23.2 \pm 0.3$ & $24.0 \pm 0.2$ \\
\hline \multicolumn{7}{|l|}{ UL-94 } \\
\hline Classification & HB & $\mathrm{HB}$ & $\mathrm{HB}$ & $\mathrm{HB}$ & $\mathrm{HB}$ & $\mathrm{HB}$ \\
\hline $\begin{array}{l}\text { Burn speed / } \\
\mathrm{mm} \mathrm{s}^{-1}\end{array}$ & $31.7 \pm 3.6$ & $38.3 \pm 2.9$ & $29.5 \pm 1.9$ & $34.0 \pm 1.8$ & $30.0 \pm 1.6$ & $19.6 \pm 3.6$ \\
\hline
\end{tabular}

b)

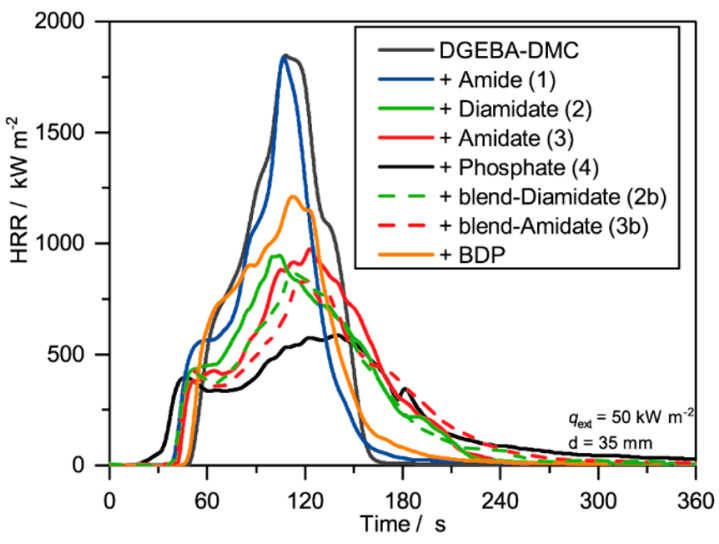

c)

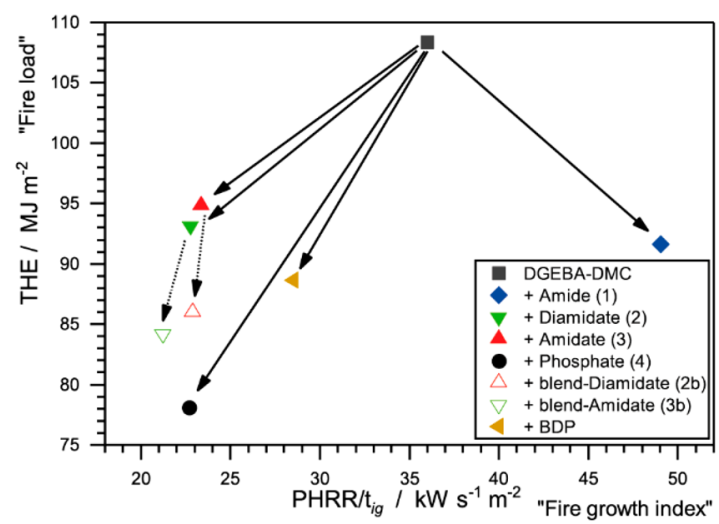

d)
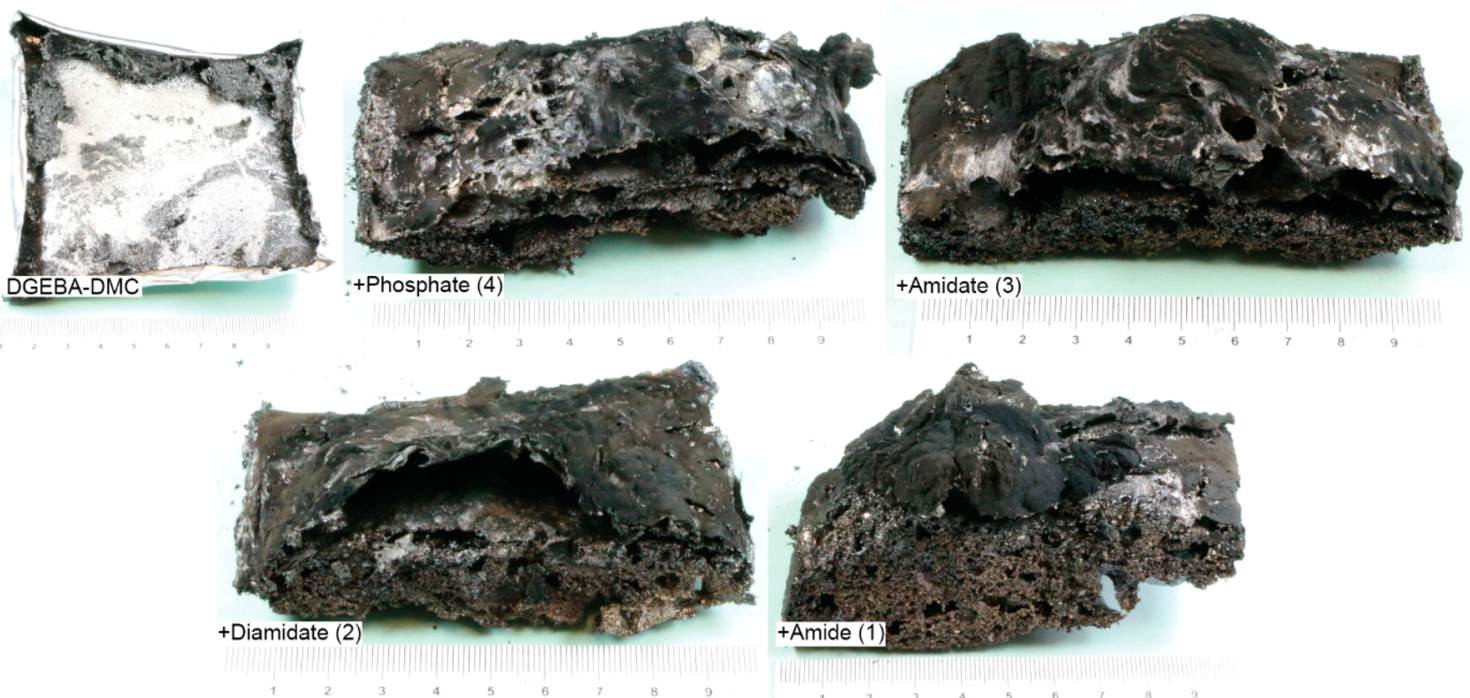

Figure 3. Cone calorimeter, UL-94, and limiting oxygen index (LOI) tests of the epoxy resins. (a) Summarized results of LOI and UL-94 tests, with all flame retardants increasing the OI and achieving HB classification in the UL-94 test. (b) Heat release rate over time of epoxy resins, with the phosphate (4) presenting the lowest peak heat release and the amide (1) the highest. (c) Petrella plot of the different epoxy resins with all flame retardants having a positive effect (lowering THE), especially the phosphate (4) lowering both fire load and fire growth index and the amide (1) only lowering the former. (d) Photos of char residue after cone calorimeter test: the epoxy resin has almost no residue; pore size decreases from phosphate (4) to amide (1) along with an increase in char residue.

oxygen index (LOI) and the Underwriter's 94 (UL-94) test, as well as forced-flaming conditions via cone calorimetry. LOI measures the lowest oxygen concentration necessary to sustain combustion in a candle-like setup, while UL-94 measures dripping and flame-spread behavior in vertical and horizontal positions.

The pure epoxy resin exhibited an oxygen index (OI) of OI $=18.7 \mathrm{vol} \%$, proving the inherent flammability of these materials. When a FR was incorporated, the OI increased to approximately OI $=23-24$ vol $\%$, corresponding to a relative increase of ca. $22-28 \%$. The addition of any of the tested FRs increased the OI and slowed down the flame spread and thereby reduced the fire hazard. However, the differences between all tested materials are minimal, mostly due to the relatively low FR loading (10 wt \%) and low P content of a sample ( $\sim 1 \% \mathrm{P}$ in each resin). The P-FRs performed on an equal level to the benchmark epoxy resin with BDP, indicating that the burning behavior in OI tests can only be altered with 
higher loading/higher $\mathrm{P}$ content in order attain OI > 27-29 vol \%. This is needed to fulfill the demands of diverse flameretardancy requirements. ${ }^{14} \mathrm{~A}$ similar behavior was obtained from UL-94 tests, where the benchmark BDP-loaded epoxy resin failed vertical tests and only achieved an $\mathrm{HB}$ rating in horizontal tests (lowest rating before not passing) due to the high flammability of epoxy resins. The herein-prepared resins with P-FRs achieved the same rating, although not all FRs managed to reduce the horizontal burn speed; most noticeably, the resin with phosphoramide (1) was barely within the margin of error of passing HB classification. In all UL-94 tests, the strong formation of char was visible for the prepared resins with P-FRs, yet the increase of viscosity of the epoxy resin resulted in the protective char dripping away from the sample. These results illustrate that at $10 \mathrm{wt} \%$ loading the FRs cannot stop vertical flame spread due to melt dripping although a strong char formation is visible. Similar to LOI, better classification can be achieved with higher FR loading or higher $\mathrm{P}$ content of the sample.

Cone calorimetry measurements proved a significant effect of all P-FRs on epoxy resins during a simulated fire scenario. The epoxy plates $\left(10 \times 10 \times 0.4 \mathrm{~cm}^{3}\right)$ were irradiated with a heat flux of $50 \mathrm{~kW} \mathrm{~m}^{-2}$ at a distance of $35 \mathrm{~mm}$, simulating a developing fire. ${ }^{28}$ The results of the forced-flaming condition experiments underlined that the epoxy resin burned with a high heat release rate (HRR) and lost $99.3 \mathrm{wt} \%$ of its mass, presenting nearly no residue (Figure $3 \mathrm{~d}$ ). All flame-retarded resins exhibited a clear reduction of peak or heat release rate (PHRR), an increase in residue yield, a lowering of the total heat evolved $(\mathrm{THE}=$ total heat released $(\mathrm{THR})$ at flame out $)$, and a reduction of fire growth rate (FIGRA = maximum $($ HRR/t)) (Figure 3b,c and Table S4). The epoxy resin loaded with the phosphate (4) demonstrated the lowest PHRR (855 $\mathrm{kW} \mathrm{m}^{-2}$, reduced by $48 \%$ ) and THE (78.1 $\mathrm{MJ} \mathrm{m}^{-2}$, reduced by $28 \%$ ) and displayed a HRR curve corresponding to a charring material with a protective layer. This behavior was clearly visible during the experiments as well as in the cross sections of the residues, as the decomposition of the resin with 4 and the volatilization of its products acted as blowing agents, creating a voluminous intumescent char that shielded the underlying material from the heat source. With increasing $\mathrm{P}-$ $\mathrm{N}$ content of the FR, a lower reduction of PHRR and THE was detected. 1, 2, and 3 showed a small plateau at $t=60 \mathrm{~s}$, but the lack of blowing agent created a char layer, which was unable to shield the underlying material, leading to additional decomposition of the epoxy and thus a higher PHRR. Epoxy resins with 1 as the additive even had a higher PHRR $\left(1832 \mathrm{~kW} \mathrm{~m}^{-2}\right)$ than the neat epoxy resin $\left(1696 \mathrm{~kW} \mathrm{~m}^{-2}\right)$. However, the residue yields of epoxy resins loaded with $\mathbf{1}(8.4 \mathrm{wt} \%)$ was in a similar range as the best performing epoxy loaded with $4(9.2$ wt \%).

All flame-retarded epoxy resins revealed an increase in residue yield compared to the epoxy resin without FRs. In pyrolysis investigations, TGA experiments of the pure FRs demonstrated that 1 presented a large amount of residue while 4 hardly left any. The increase in residue was proportional to the increase in $\mathrm{P}-\mathrm{N}$ bonds, i.e., $4<3<2<1$. In forced flaming conditions, this trend was not clearly visible. However, as has been proven in previous experiments, ${ }^{29}$ the residue yields of pure FRs in TGA experiments do not necessarily correlate with the residue yields of flame-retarded resins. Specifically, the interactions between FR and matrix govern the residue yield. For the flame-retarded epoxy resins, although residue yields were in the order $4>2>1>3$, the increased residue amount for resins with 4 can be explained by the formation of a protective layer which reduces the mass transfer of combustible material into the flame zone and shields underlying material from thermal radiation. For the nitrogencontaining compounds, the previously noted trend was also seen, especially given the margin of error for resins with 2, illustrating that residue yields increase with increasing nitrogen content in the binding sphere of phosphorus.

The effective heat of combustion (EHC) is the quotient of the total heat evolved and the total mass loss; therefore, it is a ratio between these two values. In cone calorimetry experiments, the EHC relates to flame dilution and flame inhibition, and a reduction in EHC is a parameter for the gas phase activity of a FR. ${ }^{23}$ The phosphate (4) displayed a reduction in EHC of $\sim 20 \%$, from $29.6 \mathrm{MJ} \mathrm{kg}^{-1}$ for the epoxy resin to $21.6 \mathrm{MJ} \mathrm{kg}^{-1}$ for the resin with 4 , which points to gas phase activity of the FR (Figure 4b). Noticeably, this effect is

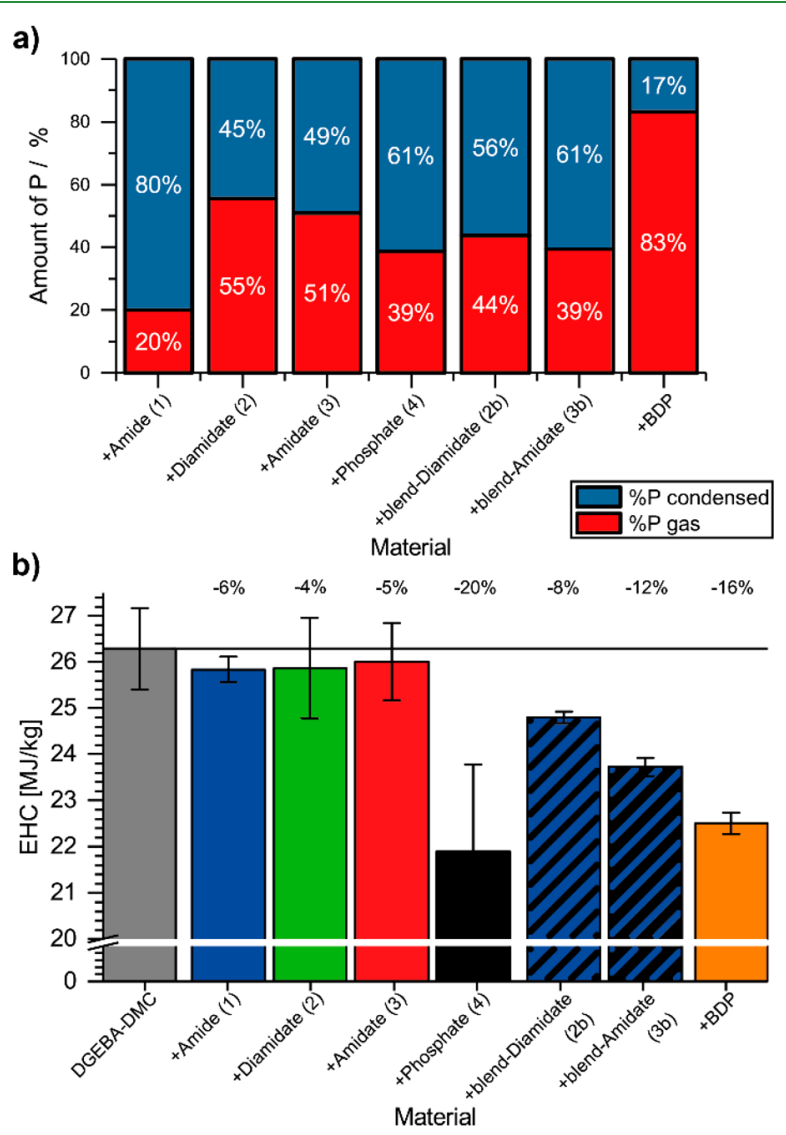

Figure 4. (a) Phosphorus content determined by elemental analysis from the residues after cone calorimeter tests (blue bars). Calculated amount of phosphorus in the gas phase (red bars). (b) Comparison of effective heat of combustion (EHC) of epoxy resins with and without FRs. The numbers above the bars represent the relative change to the non-flame-retarded epoxy resin.

minimized if $\mathrm{P}-\mathrm{N}$ bonds were installed into the $\mathrm{FR}$, as $\mathbf{1}, \mathbf{2}$, and 3 reduced the EHC only by ca. $4-5 \%$, indicating that the gas phase activity of the synthesized P-FRs decreased with the presence of nitrogen in the chemical structure. Although residue yields of resins with $1,2,3$, and 4 are within the same range (ca. 8-10 wt \% mass loss), the ratios between the THEs and total mass loss changed. This change resulted from flame dilution and flame inhibition effects which affect THE. The 
Scheme 1. Scheme of Proposed Decomposition and Reaction Pathways of P-O- and P-N-Containing Phosphorus Flame Retardants $^{a}$

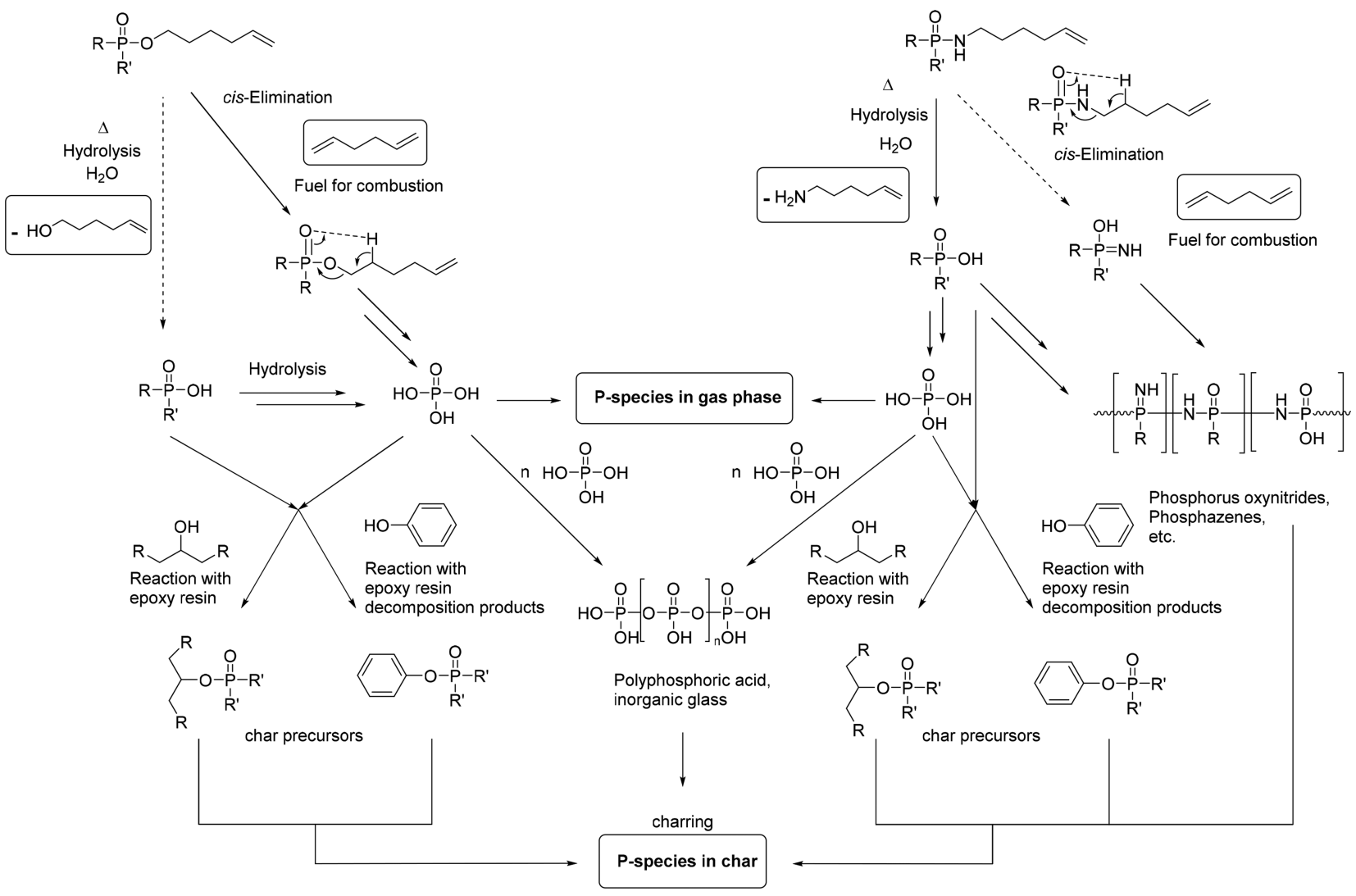

${ }^{a} \mathrm{P}-\mathrm{O}$ containing P-FRs are more prone to cis-elimination, resulting in the formation of phosphoric acid and enabling transesterification reactions. $\mathrm{P}-\mathrm{N}$-containing P-FRs are more to hydrolysis, resulting in the formation of phosphorus oxynitrides and phosphazenes. Products in squares were identified via TG-FTIR and pyrolysis GC-MS.

blended FRs ( $\mathbf{2} \mathbf{b}$ and $\mathbf{3 b}$ ) were also tested in epoxy resins, and the results were compared to resins with 2 and 3 . The results show that the blended FRs achieved higher residue yields a lower PHRR, decreased THE, and a lower EHC than resins with only 2 or 3 . In fact, the PHRR of the resins with $\mathbf{2 b}$ or $\mathbf{3 b}$ are comparable to the resins loaded with 4 which showed the strongest reduction of this value compared to the epoxy resin. Resins with $3 \mathrm{~b}$ had a $15 \%$ lower PHRR than resins with 3, while resins with $\mathbf{2 b}$ or $\mathbf{3 b}$ demonstrated $8 \%$ or $11 \%$ lower THE values and residue yields $47 \%$ or $49 \%$ higher than resins with only $\mathbf{2}$ or $\mathbf{3}$, respectively. Consequently, the EHCs of resins with $\mathbf{2 b}$ or $\mathbf{3 b}$ are $4 \%$ or $7 \%$ lower than resins with $\mathbf{2}$ or 3, respectively. Noticeably, the fire growth rate (FIGRA) of resins with $\mathbf{2 b}$ are $20 \%$ lower than resins with 2 . These results clearly demonstrate that the presence of two types of P-FRs in epoxy resins increases FR efficacy compared to a single P-FR with the same O:N ratio. In the case of 2 and 3 , the $\mathrm{P}-\mathrm{N}$ linkages retain the phosphorus in the condensed phase, forming char during decomposition (Scheme 1, right pathway). This retention of $\mathrm{P}$ in the char reduces flame inhibition as $\mathrm{P}$ retention in the condensed phase competes with $\mathrm{P}$ release in the gas phase. $^{23}$

The residues after cone calorimeter tests were analyzed for their phosphorus content via elemental analysis, indicating the largest amount of $\mathrm{P}(80 \%)$ in the condensed phase for resins loaded with 1 (Figure 4a). The difference in gas and condensed phase activity is explained by the different decomposition mechanisms as discussed previously.
In epoxy resins, the phosphate (4) readily forms phosphoric acid via cis-elimination and creates networks with aromatic char in the condensed phase and is present at the main decomposition step due to incorporation into the decomposing matrix via esterification (Scheme 1). In contrast, the phosphoramide (1) was hydrolyzed under these conditions. However, 1 also generated polymeric compounds containing phosphazene or phosphorus oxynitride components in the condensed phase, as indicated by solid-state NMR (Figure S46), leading to an increased residue and high $\mathrm{P}$ content in the char. The phosphoramidate (3) and phosphorodiamidate (2), containing both $\mathrm{P}-\mathrm{O}$ and $\mathrm{P}-\mathrm{N}$ bonds, exhibit both decomposition mechanisms with decreasing cis-elimination when the $\mathrm{P}-\mathrm{N}$ content increases and transesterification (compare the pyrolysis GC-MS data).

The effect of combining phosphate and amide led to synergistic flame-retardant effects, which were not observed for the combination of $\mathrm{P}-\mathrm{O}$ and $\mathrm{P}-\mathrm{N}$ in a single $\mathrm{FR}$ additive. The exchange of $\mathrm{P}-\mathrm{O}$ bonds with $\mathrm{P}-\mathrm{N}$ bonds reduced the effectiveness of one mechanism but did not sufficiently promote the other. This conclusion was exemplified in the amount of residue in cone calorimeter tests as well as the $\mathrm{P}$ content of the residue (Figure $4 \mathrm{a}$ ): the residue amounts in epoxy resins were ordered $4 \geq 2>1>3$ (i.e., $9.2 \% \geq 5.0 \%>$ $8.4 \%>7.6 \%$ ) and $\mathbf{2 b}>\mathbf{3 b}>\mathbf{4}>\mathbf{1}$ (i.e., $13.4 \%>11.3 \%>9.2 \%$ $>8.4 \%)$ for the blended materials, showing an increase in residue for the blended FRs. As for P content in the condensed phase, the amidate (3) and diamidate (2) showed lower 


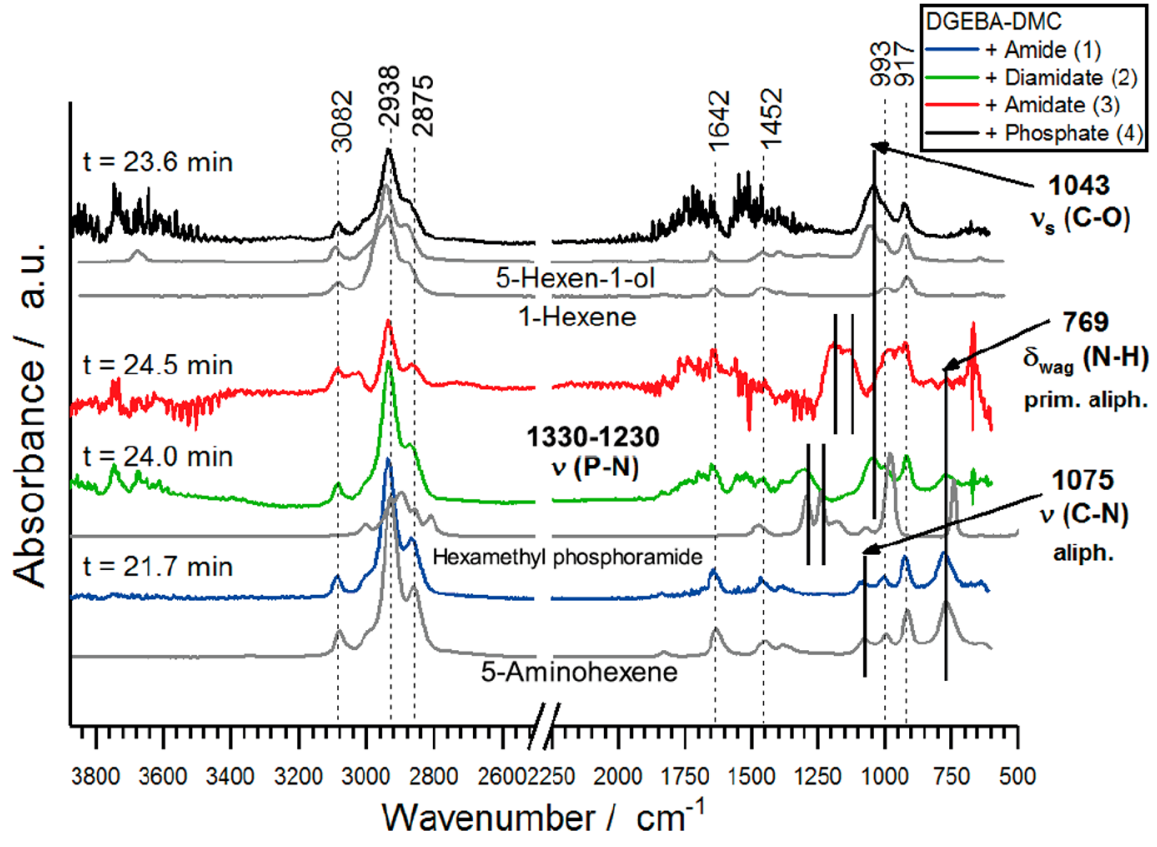

Figure 5. TG-FTIR spectra of the first decomposition step of flame-retarded epoxy resins.

amounts of $\mathrm{P}$ in their residues (49\% and $45 \%$, respectively) than the blended FRs $\mathbf{3 b}$ and $\mathbf{2 b}$ ( $61 \%$ and $56 \%$, respectively).

The FTIR spectra of the evolved gases during the first decomposition step (Figure 5) showed that the FRs decompose above $200{ }^{\circ} \mathrm{C}$, and some decomposition products enter the gas phase, which is a typical behavior for low molecular weight FRs. ${ }^{22}$ Looking at the main decomposition step at around $360{ }^{\circ} \mathrm{C}$ (Figure S21), TG-FTIR showed the DGEBA-DMC decomposition pattern, ${ }^{30}$ pointing to the degradation of the resin matrix. An exception was the epoxy resin with 4, where the phosphate still displayed characteristic bands during the main decomposition step, implying the presence of phosphate beyond the FR's boiling point. This phenomenon was caused by the reaction between matrix and phosphate (Scheme 1), as the phosphate was more likely to produce phosphoric acid than the nitrogen-containing counterparts due to the difference in bond dissociation energies, leading to incorporation of phosphates into the polymer matrix by transesterification.

Hot stage FTIR spectra (Figure S27) of the condensed phase at various temperatures implied the presence of phosphorus species in the residue (Table S3). All resins containing FRs exhibited bands corresponding to various phosphorus species at $600{ }^{\circ} \mathrm{C}$, i.e., at end of the test. These bands were not detected in the epoxy resin, indicating condensed phase activity for all tested FRs. For 4, the presence of medium intensity bands at $1181 \mathrm{~cm}^{-1}$, corresponding to C$\mathrm{O}$ stretching vibration of phenols, and at $828 \mathrm{~cm}^{-1}$, corresponding to $\mathrm{C}-\mathrm{H}$ bonds of aromatic rings, point to the formation of substituted aromatic compounds in the condensed phase. The band was strongest for 4 , which points to the ability of the phosphate to bind hydroxyl-functionalized aromatic rings during the decomposition of the matrix into the condensed phase. In contrast, all nitrogen-containing FRs (13) demonstrated a medium intensity band at $1398 \mathrm{~cm}^{-1}$, which corresponds to $\mathrm{P}=\mathrm{N}-\mathrm{P}$ or $\mathrm{P}-\mathrm{N}-\mathrm{Ph}$ vibrations, which are probably attributed to polyphosphazenes or phosphor oxynitride in the condensed phase, as underlined by a higher amount of residue after the TGA experiments for N-containing FRs.

\section{CONCLUSION}

A systematic library of phosphorus-containing flame-retardant (FR) additives (1-4) with precisely adjusted $\mathrm{P} / \mathrm{N} / \mathrm{O}$ ratio were synthesized. Compounds 1-4 were less toxic than their halogenated counterpart for most end points, and compounds 2 and 4 represented the best alternatives. With this library, the decomposition pathway of the FRs in an epoxy resin during combustion was controlled.

By a combination of different techniques, we were able to elucidate the degradation mechanism of the different P-FRs and proved a gradual change of the decomposition depending on the chemical structure. In a simulated fire scenario, the phosphate (4) exhibited the highest efficiency in epoxy resins and was active in both the gas and the condensed phase effectively. The gas phase activity was explained by the predominant cis-elimination mechanism during the combustion (from pyrolysis GC-MS). With an exchange of $\mathrm{P}-\mathrm{O}$ bonds with $\mathrm{P}-\mathrm{N}$ bonds, the amount of cis-elimination decreased and hydrolysis increased as a decomposition pathway. The amide (1) with three $\mathrm{P}-\mathrm{N}$ bonds proved the highest condensed phase activity of the investigated structures due to cleavage of the $\mathrm{P}-\mathrm{N}$ bonds during the combustion. This also resulted in the lowest FR performance of 1 . Notably, the blends of phosphate and phosphoramide ( $2 \mathbf{b}$ and $\mathbf{3 b}$ ) outperformed the pure 2 and 3 . We believe this is an effect of combining different decomposition mechanisms, which leads to synergistic flame retardancy. These findings will further contribute to the development of systematic libraries of Pbased FRs with low toxicity and high efficiency.

\section{EXPERIMENTAL SECTION}

Tri(hex-5-en-1-yl)phosphate (4). To a dried three-necked, 2 L round-bottom flask fitted with a dropping funnel, 5-hexen-1-ol (274.2 $\mathrm{mL}, 2.28 \mathrm{~mol}, 3.5$ equiv) and triethylamine $(318.6 \mathrm{~mL}, 2.28 \mathrm{~mol}, 3.5$ equiv) were added under an argon atmosphere in dry dichloromethane $(500 \mathrm{~mL})$. Then phosphoryl chloride $(60.6 \mathrm{~mL}, 0.65 \mathrm{~mol}$, 
1.0 equiv) dissolved in dry dichloromethane $(50 \mathrm{~mL})$ was added dropwise to the solution, keeping the temperature at $0{ }^{\circ} \mathrm{C}$. The reaction was allowed to stir overnight at room temperature and was then filtered. Afterward, the crude mixture was concentrated at reduced pressure, dissolved in toluene and then filtered to remove most of the ammonium salt byproduct. Then, the crude product was washed with $10 \%$ aqueous hydrochloric acid solution, a saturated solution of calcium carbonate, and brine. The organic layer was dried over anhydrous sodium sulfate, filtered, and dried in vacuo.

For the biological tests the compound $\mathbf{4}$ was purified by chromatography over neutral alumina oxide using diethyl ether as eluent to give a clear, slight yellow oil (yield: 95\%). The purity and chemical structure were determined by ${ }^{1} \mathrm{H}$ NMR, ${ }^{13} \mathrm{C}\{\mathrm{H}\}$ NMR, and ${ }^{31} \mathrm{P}\{\mathrm{H}\}$ NMR spectroscopy as well as electrospray ionization mass spectrometry (ESI-MS).

${ }^{1} \mathrm{H}$ NMR (300 MHz, chloroform- $d, \delta$ ): 5.83-5.70 (m, 3H, e), $5.02-4.93(\mathrm{~m}, 6 \mathrm{H}, \mathrm{f}), 4.02(\mathrm{q}, 6 \mathrm{H}, \mathrm{a}), 2.10-2.03(\mathrm{td}, 6 \mathrm{H}, \mathrm{d}), 1.68(\mathrm{tt}$, $6 \mathrm{H}, \mathrm{b}), 1.46(\mathrm{tt}, 6 \mathrm{H}, \mathrm{c}) .{ }^{31} \mathrm{P}\{\mathrm{H}\}$ NMR $(121 \mathrm{MHz}$, chloroform-d, $\delta)$ : $-0.67(\mathrm{~s}, 1 \mathrm{P}, 1) .{ }^{13} \mathrm{C}\{\mathrm{H}\}$ NMR (75 MHz, chloroform- $\left.d, \delta\right): 138.17$ (s, 3C, e), 114.85 (s, 3C, f), 67.38 (d, 3C, a), 33.11 (s, 3C, d), 29.60 $(\mathrm{d}, 3 \mathrm{C}, \mathrm{b}), 24.67(\mathrm{~s}, 3 \mathrm{C}, \mathrm{c})$. ESI-MS: $345.21[\mathrm{M}+\mathrm{H}]^{+}$(calculated M $+: 344.21)$.

Tri(hex-5-en-1-yl)phosphoramide (1). To a dried three-necked, $2 \mathrm{~L}$ round-bottom flask fitted with a dropping funnel, hex-5-en-1amine $(286.2 \mathrm{~mL}, 2.28 \mathrm{~mol}, 3.5$ equiv) and triethylamine $(318.6 \mathrm{~mL}$, $2.28 \mathrm{~mol}, 3.5$ equiv) were added under an argon atmosphere in dry dichloromethane $(500 \mathrm{~mL})$. Then, phosphoryl chloride $(60.6 \mathrm{~mL}$, $0.65 \mathrm{~mol}, 1.0$ equiv) dissolved in dry dichloromethane $(50 \mathrm{~mL})$ was added dropwise to the solution, keeping the temperature at $0{ }^{\circ} \mathrm{C}$. The reaction was allowed to stir overnight at room temperature and was then filtered. Afterward, the crude mixture was concentrated at reduced pressure and then filtered for the second time. The crude product was redissolved in diethyl ether $(200 \mathrm{~mL})$ and stored overnight at $-20{ }^{\circ} \mathrm{C}$. The solution was filtered again to remove the triethylamine hydrochloride completely. The crude product was washed with $10 \%$ aqueous hydrochloric acid solution, a saturated solution of calcium carbonate, and brine. The organic layer was dried over anhydrous sodium sulfate, filtered, and dried in vacuo.

For the biological tests the compound $\mathbf{1}$ was purified by chromatography over silica using DCM and methanol (9:1) as eluent to give a clear, slight yellow oil (yield: $92 \%$ ). The purity and chemical structure were determined by ${ }^{1} \mathrm{H} N M R,{ }^{13} \mathrm{C}\{\mathrm{H}\} \mathrm{NMR}$, and ${ }^{31} \mathrm{P}\{\mathrm{H}\}$ NMR spectroscopy as well as electrospray ionization mass spectrometry (ESI-MS).

${ }^{1} \mathrm{H}$ NMR (300 MHz, chloroform- $d, \delta$ ): 5.81-5.68 (m, 3H, e), $4.98-4.89$ (m, 6H, f), 2.85 (quint, $6 \mathrm{H}, \mathrm{a}), 2.36-2.29(\mathrm{q}, 3 \mathrm{H}, \mathrm{g})$, $2.05-1.98(\mathrm{td}, 6 \mathrm{H}, \mathrm{d}), 1.48-1.34(\mathrm{~m}, 12 \mathrm{H}, \mathrm{b}, \mathrm{c}) .{ }^{31} \mathrm{P}\{\mathrm{H}\} \operatorname{NMR}(121$ $\mathrm{MHz}$, chloroform- $d, \delta): 16.67(\mathrm{~s}, 1 \mathrm{P}, 1) .{ }^{13} \mathrm{C}\{\mathrm{H}\}$ NMR $(75 \mathrm{MHz}$, chloroform- $d, \delta$ ): 138.50 (s, 3C, e), 114.67 (s, 3C, f), 41.09 (s, 3C, a), 33.39 (s, 3C, d), 31.69 (d, 3C, b), 26.09 (s, 3C, c). ESI-MS: 342.24 $\left.[\mathrm{M}+\mathrm{H}]^{+}, 683.44[2 \mathrm{M}+\mathrm{H}]^{+}\right)$(calculated: 341.26).

Hex-5-en-1-yl Phosphorodichloridate. To a dried threenecked, $250 \mathrm{~mL}$ round-bottom flask fitted with a dropping funnel, phosphoryl chloride ( $18.7 \mathrm{~mL}, 205.00 \mathrm{mmol}, 10.0$ equiv) was added under an argon atmosphere in dry toluene $(50 \mathrm{~mL})$. Then triethylamine $(2.8 \mathrm{~mL}, 20.50 \mathrm{mmol}, 1.0$ equiv) and 5-hexen-1-ol $(2.5 \mathrm{~mL}, 20.50 \mathrm{mmol}, 1.0$ equiv) dissolved in dry toluene $(5 \mathrm{~mL})$ were added dropwise to the solution, keeping the temperature at $0{ }^{\circ} \mathrm{C}$. The reaction was stirred $1 \mathrm{~h}$ at room temperature. Afterward, the crude product was concentrated at reduced pressure and filtered to remove the triethylammonium chloride. Then, all byproducts and starting material were removed under reduced pressure $\left(\mathrm{RT}, 5 \times 10^{-2}\right.$ mbar). The product was used without any further purification.

Di(hex-5-en-1-yl)phosphorochloridate. To a dried threenecked $250 \mathrm{~mL}$ round-bottom flask fitted with a dropping funnel, phosphoryl chloride $(8.1 \mathrm{~mL}, 88.89 \mathrm{mmol}, 1.0$ equiv) was added under an argon atmosphere in dry toluene $(80 \mathrm{~mL})$. Then triethylamine $(22.2 \mathrm{~mL}, 160.00 \mathrm{mmol}, 1.8$ equiv) and 5-hexen-1-ol $(19.2 \mathrm{~mL}, 160.00 \mathrm{mmol}, 1.8$ equiv) dissolved in dry toluene $(20 \mathrm{~mL})$ were dropwise to the solution, keeping the temperature at $0{ }^{\circ} \mathrm{C}$. The reaction was allowed to stir overnight at room temperature and was then filtered. Afterward, the crude mixture was concentrated at reduced pressure.

The compound was purified by distillation $\left(90^{\circ} \mathrm{C},<10^{-1}\right.$ mbar 30 min; $110^{\circ} \mathrm{C},<10^{-1} \mathrm{mbar} 15-20 \mathrm{~min}$ ) to give a clear, slight yellow oil (yield: $82 \%$ ). The purity and chemical structure were determined by ${ }^{1} \mathrm{H}$ NMR and ${ }^{31} \mathrm{P}\{\mathrm{H}\}$ NMR spectroscopy.

${ }^{1} \mathrm{H}$ NMR (300 MHz, chloroform- $d, \delta$ ): 5.78-5.65 (m, $\left.2 \mathrm{H}, \mathrm{e}\right)$, 4.98-4.89 (m, 4H, f), 4.21-1.09 (m, 4H, a), 2.02 (td, 4H, d), 1.69 $(\mathrm{tt}, 4 \mathrm{H}, \mathrm{b}), 1.45(\mathrm{tt}, 4 \mathrm{H}, \mathrm{c}) .{ }^{31} \mathrm{P}\{\mathrm{H}\}$ NMR $(121 \mathrm{MHz}$, chloroform- $d$, $\delta): 4.73(\mathrm{~s}, 1 \mathrm{P}, 1)$.

Tri(hex-5-en-1-yl)phosphorodiamidate (2). To a dried threenecked $250 \mathrm{~mL}$ round-bottom flask fitted with a dropping funnel, hex5-en-1-yl phosphorodichloridate ( $4.5 \mathrm{~g}, 20.50 \mathrm{mmol}, 1.0$ equiv) was added under an argon atmosphere in dry toluene $(50 \mathrm{~mL})$. Then hex5-en-1-amine (5.4 mL, $43.05 \mathrm{mmol}, 2.1$ equiv) and triethylamine $(6.0$ $\mathrm{mL}, 43.05 \mathrm{mmol}, 2.1$ equiv) were added dropwise to the solution, keeping the temperature at $0{ }^{\circ} \mathrm{C}$. The reaction was allowed to stir overnight at room temperature and was then filtered. The crude mixture was concentrated at reduced pressure, and the crude product was dissolved in diethyl ether to wash it with $10 \%$ aqueous hydrochloric acid solution, a saturated solution of calcium carbonate, and brine. The organic layer was dried over anhydrous sodium sulfate, filtered, and concentrated on the rotary evaporator.

For the biological tests the compound $\mathbf{2}$ was purified by chromatography over silica using ethyl acetate, petroleum ether, and methanol (9:1:0.1) as eluent to give a clear, slight yellow oil (yield: $95 \%$ ). The purity and chemical structure were determined by ${ }^{1} \mathrm{H}$ NMR, ${ }^{13} \mathrm{C}\{\mathrm{H}\} \mathrm{NMR}$, and ${ }^{31} \mathrm{P}\{\mathrm{H}\}$ NMR spectroscopy as well as electrospray ionization mass spectrometry (ESI-MS).

${ }^{1} \mathrm{H}$ NMR (300 MHz, chloroform-d, $\delta$ ): 5.76-5.63 (m, 3H, f, l), 4.94-4.84 (m, 6H, g, m), 3.83 (q, 2H, h), 2.78 (q, 4H, b), 2.61 (br, $2 \mathrm{H}, \mathrm{a}), 1.98(\mathrm{~m}, 6 \mathrm{H}, \mathrm{e}, \mathrm{k}), 1.57$ (m, 2H, (i), 1.44-1.29 (m, 6H, c, d, j). ${ }^{31} \mathrm{P}\{\mathrm{H}\} \operatorname{NMR}(121 \mathrm{MHz}$, chloroform-d, $\delta): 15.81(\mathrm{~s}, 1 \mathrm{P}, 1) \cdot{ }^{13} \mathrm{C}$ $\{\mathrm{H}\}$ NMR (75 MHz, chloroform- $d, \delta): 138.44$ (s, 2C, f), 138.36 (s, C, 1), 114.73 (s, C, m), 114.65 (s, 2C, g), 64.61 (d, C, h), 41.01 (s, 2C, b), 33.32 (s, 2C, e), 33.25 (s, C, k), 31.43 (d, 2C, c), 29.99 (d, C, (i), 25.96 (s, 2C, d), 24.97 (s, C, j). ESI-MS $m / z: 343.24[\mathrm{M}+\mathrm{H}]^{+}$, $685.42[2 \mathrm{M}+\mathrm{H}]^{+}$(calculated: 342.24$)$.

Tri(hex-5-en-1-yl)phosphoramidate (3). To a dried threenecked $250 \mathrm{~mL}$ round-bottom flask fitted with a dropping funnel, di(hex-5-en-1-yl)phosphorochloridate ( $25.0 \mathrm{~g}, 88.9 \mathrm{mmol}, 1.0$ equiv) was added under an argon atmosphere in dry toluene $(80 \mathrm{~mL})$. Then triethylamine (13.6 mL, $97.78 \mathrm{mmol}, 1.1$ equiv) and 1-hexene-5amine ( $12.3 \mathrm{~mL}, 97.78 \mathrm{mmol}, 1.1$ equiv) were added dropwise to the solution at room temperature. The reaction was stirred overnight and filtered. The crude mixture was concentrated at reduced pressure, and the crude product was dissolved in diethyl ether to wash it with $10 \%$ aqueous hydrochloric acid solution, a saturated solution of calcium carbonate, and brine. The organic layer was dried over anhydrous sodium sulfate, filtered, and dried in vacuo.

For the biological tests the compound was purified by chromatography over silica using ethyl acetate and petroleum ether (6:4) as an eluent to give a clear, slight yellow oil (yield: 63\%). The purity and chemical structure were determined by ${ }^{1} \mathrm{H} N M R,{ }^{13} \mathrm{C}\{\mathrm{H}\}$ NMR, and ${ }^{31} \mathrm{P}\{\mathrm{H}\}$ NMR spectroscopy.

${ }^{1} \mathrm{H}$ NMR (300 MHz, chloroform- $d, \delta$ ): 5.83-5.69 (m, 3H, e, l), 5.01-4.91 (m, 6H, f, m), 3.95 (m, 4H, a), 2.70 (br, H, g), 2.85 (br, $2 \mathrm{H}, \mathrm{h}), 2.04$ (td, 6H, d, k), $1.66(\mathrm{~m}, 4 \mathrm{H}, \mathrm{b}), 1.50-1.35(\mathrm{~m}, 8 \mathrm{H}, \mathrm{c}, \mathrm{i}, \mathrm{j})$. ${ }^{31} \mathrm{P}\{\mathrm{H}\}$ NMR $(121 \mathrm{MHz}$, chloroform- $d, \delta): 9.48(\mathrm{~s}, 1 \mathrm{P}, 1) .{ }^{13} \mathrm{C}\{\mathrm{H}\}$ NMR (75 MHz, chloroform- $d, \delta$ ): 138.47 (s, C, 1), 138.41 (s, 2C, e), 114.87 (s, 2C, f), 114.81 (s, C, m), 66.06 (d, 2C, a), 41.33 (s, C, h), 33.37 (s, C, k), 33.29 (s, 2C, d), 31.21 (d, C, (i), 29.90 (d, 2C, b), $25.92(\mathrm{~s}, \mathrm{C}, \mathrm{j}), 24.95$ (s, 2C; c). ASAP-MS $m / z: 689.2(2 \mathrm{M}+\mathrm{H})$ (calculated: 344.21 ). 


\section{ASSOCIATED CONTENT}

\section{S Supporting Information}

The Supporting Information is available free of charge on the ACS Publications website at DOI: 10.1021/acsapm.9b00129.

Thermal properties (DSC, TGA); ESI-MS; TG-FTIR, PCFC; UL-94; LOI; cone calorimeter details; residue morphology; NMR; biological assays (PDF)

\section{AUTHOR INFORMATION}

\section{Corresponding Authors}

*E-mail: wurm@mpip-mainz.mpg.de.

*E-mail: bernhard.schartel@bam.de.

\section{ORCID}

Alexander Battig: 0000-0002-9461-1368

Lisa Zimmermann: 0000-0001-6801-6859

Martin Wagner: 0000-0002-4402-3234

Bernhard Schartel: 0000-0001-5726-9754

Frederik R. Wurm: 0000-0002-6955-8489

\section{Author Contributions}

J.C.M. and A.B. contributed equally to this work.

\section{Notes}

The authors declare no competing financial interest.

\section{ACKNOWLEDGMENTS}

The authors thank the Deutsche Forschungsgemeinschaft (DFG WU 750/8-1; SCHA 730/15-1) for funding. J.C.M. is the recipient of a fellowship through funding of the Excellence Initiative (DFG/GSC 266) in the context of the graduate school of excellence "MAINZ" (Materials Science in Mainz). F.R.W. and J.C.M. thank Prof. Dr. Katharina Landfester (MPIP, Germany) for support. We thank Robert Graf (MPI-P, Germany) for the solid-state NMR measurements. A.B. thanks William Harris and Leticia Lima for their assistance in measuring and preparing samples. L.Z. and F.R.W. thank the German Federal Ministry for Education and Research (BMBF) for their support of the program "Research for sustainable development (FONA)", "PlastX-Plastics as a systemic risk for social-ecological supply systems" (Grant 01UU1603A).

\section{REFERENCES}

(1) Velencoso, M. M.; Battig, A.; Markwart, J. C.; Schartel, B.; Wurm, F. R. Molecular Firefighting - How Modern Phosphorus Chemistry Can Help Solve the Flame Retardancy Task. Angew. Chem., Int. Ed. 2018, 57 (33), 10450.

(2) Nishihara, H.; Tanji, S.; Kanatani, R. Interactions between Phosphorus- and Nitrogen-Containing Flame Retardants. Polym. J. 1998, 30, 163.

(3) Lindsay, C. I.; Hill, S. B.; Hearn, M.; Manton, G.; Everall, N.; Bunn, A.; Heron, J.; Fletcher, I. Mechanisms of action of phosphorus based flame retardants in acrylic polymers. Polym. Int. 2000, 49 (10), $1183-1192$.

(4) Schartel, B. Phosphorus-based Flame Retardancy MechanismsOld Hat or a Starting Point for Future Development? Materials 2010, 3 (10), 4710-4745.

(5) Green, J. A Review of Phosphorus-Containing Flame Retardants. J. Fire Sci. 1992, 10 (6), 470-487.

(6) Braun, U.; Balabanovich, A. I.; Schartel, B.; Knoll, U.; Artner, J.; Ciesielski, M.; Döring, M.; Perez, R.; Sandler, J. K. W.; Altstädt, V.; Hoffmann, T.; Pospiech, D. Influence of the oxidation state of phosphorus on the decomposition and fire behaviour of flameretarded epoxy resin composites. Polymer 2006, 47 (26), 8495-8508.
(7) Täuber, K.; Marsico, F.; Wurm, F. R.; Schartel, B. Hyperbranched poly(phosphoester)s as flame retardants for technical and high performance polymers. Polym. Chem. 2014, 5 (24), 7042-7053.

(8) Minkoff, G. J.; Tipper, C. F. H. Chemistry of Combustion Reactions; Butterworths: 1962.

(9) Gaan, S.; Sun, G.; Hutches, K.; Engelhard, M. H. Effect of nitrogen additives on flame retardant action of tributyl phosphate: Phosphorus-nitrogen synergism. Polym. Degrad. Stab. 2008, 93 (1), 99-108.

(10) Laoutid, F.; Bonnaud, L.; Alexandre, M.; Lopez-Cuesta, J. M.; Dubois, P. New prospects in flame retardant polymer materials: From fundamentals to nanocomposites. Mater. Sci. Eng., $R$ 2009, 63 (3), $100-125$.

(11) Gao, F.; Tong, L.; Fang, Z. Effect of a novel phosphorousnitrogen containing intumescent flame retardant on the fire retardancy and the thermal behaviour of poly(butylene terephthalate). Polym. Degrad. Stab. 2006, 91 (6), 1295-1299.

(12) Gaan, S.; Sun, G. Effect of phosphorus and nitrogen on flame retardant cellulose: A study of phosphorus compounds. J. Anal. Appl. Pyrolysis 2007, 78 (2), 371-377.

(13) Morgan, A. B.; Gilman, J. W. An overview of flame retardancy of polymeric materials: application, technology, and future directions. Fire Mater. 2013, 37 (4), 259-279.

(14) Grand, A. F.; Wilkie, C. A. Fire Retardancy of Polymeric Materials; CRC Press: 2000.

(15) Cho, Y.-H.; Kim, K.; Ahn, S.; Liu, H. K. Allyl-substituted triazines as additives for enhancing the thermal stability of Li-ion batteries. J. Power Sources 2011, 196 (3), 1483-1487.

(16) Lu, S.-Y.; Hamerton, I. Recent developments in the chemistry of halogen-free flame retardant polymers. Prog. Polym. Sci. 2002, 27 (8), 1661-1712.

(17) Levchik, S. V.; Weil, E. D. A Review of Recent Progress in Phosphorus-based Flame Retardants. J. Fire Sci. 2006, 24 (5), 345364.

(18) Zheng, X.-B.; Wu, J.-P.; Luo, X.-J.; Zeng, Y.-H.; She, Y.-Z.; Mai, B.-X. Halogenated flame retardants in home-produced eggs from an electronic waste recycling region in South China: Levels, composition profiles, and human dietary exposure assessment. Environ. Int. 2012, $45,122-128$.

(19) Xiao, H.; Shen, L.; Su, Y.; Barresi, E.; DeJong, M.; Hung, H.; Lei, Y.-D.; Wania, F.; Reiner, E. J.; Sverko, E.; Kang, S.-C. Atmospheric concentrations of halogenated flame retardants at two remote locations: The Canadian High Arctic and the Tibetan Plateau. Environ. Pollut. 2012, 161, 154-161.

(20) Windham, G. C.; Pinney, S. M.; Sjodin, A.; Lum, R.; Jones, R. S.; Needham, L. L.; Biro, F. M.; Hiatt, R. A.; Kushi, L. H. Body burdens of brominated flame retardants and other persistent organohalogenated compounds and their descriptors in US girls. Environ. Res. 2010, 110 (3), 251-257.

(21) Nguyen, T.-M.; Chang, S.; Condon, B.; Slopek, R.; Graves, E.; Yoshioka-Tarver, M. Structural Effect of Phosphoramidate Derivatives on the Thermal and Flame Retardant Behaviors of Treated Cotton Cellulose. Ind. Eng. Chem. Res. 2013, 52 (13), 4715-4724.

(22) Perret, B.; Pawlowski, K. H.; Schartel, B. Fire retardancy mechanisms of arylphosphates in polycarbonate (PC) and PC/ acrylonitrile-butadiene-styrene. J. Therm. Anal. Calorim. 2009, 97 (3), 949.

(23) Schartel, B.; Perret, B.; Dittrich, B.; Ciesielski, M.; Krämer, J.; Müller, P.; Altstädt, V.; Zang, L.; Döring, M. Flame Retardancy of Polymers: The Role of Specific Reactions in the Condensed Phase. Macromol. Mater. Eng. 2016, 301 (1), 9-35.

(24) Rakotomalala, M.; Wagner, S.; Döring, M. Recent Developments in Halogen Free Flame Retardants for Epoxy Resins for Electrical and Electronic Applications. Materials 2010, 3 (8), 4300.

(25) Ciesielski, M.; Schäfer, A.; Döring, M. Novel efficient DOPObased flame-retardants for PWB relevant epoxy resins with high glass transition temperatures. Polym. Adv. Technol. 2008, 19 (6), 507-515.

(26) Cowie, J. M. G.; Arrighi, V. Polymers: Chemistry and Physics of Modern Materials, 3rd ed.; CRC Press: 2007. 
(27) Schartel, B.; Wilkie, C. A.; Camino, G. Recommendations on the scientific approach to polymer flame retardancy: Part 1Scientific terms and methods. J. Fire Sci. 2016, 34 (6), 447-467.

(28) Schartel, B.; Hull, T. R. Development of fire-retarded materials-Interpretation of cone calorimeter data. Fire Mater. 2007, 31 (5), 327-354.

(29) Wawrzyn, E.; Schartel, B.; Ciesielski, M.; Kretzschmar, B.; Braun, U.; Döring, M. Are novel aryl phosphates competitors for bisphenol A bis(diphenyl phosphate) in halogen-free flame-retarded polycarbonate/acrylonitrile-butadiene-styrene blends? Eur. Polym. J. 2012, 48 (9), 1561-1574.

(30) Schartel, B.; Perret, B.; Dittrich, B.; Ciesielski, M.; Krämer, J.; Müller, P.; Altstädt, V.; Zang, L.; Döring, M. Flame Retardancy of Polymers: The Role of Specific Reactions in the Condensed Phase. Macromol. Mater. Eng. 2016, 301 (1), 9-35. 